\section{GPS TRACKING OF QUAD BIKE USE ON AUSTRALIAN} DAIRY FARMS

doi:10.1136/injuryprev-2012-040580d.42

${ }^{1} \mathrm{~T}$ Lower*, ${ }^{2} \mathrm{M}$ Trotter. ${ }^{1}$ Australian Centre for Agricultural Health and Safety (University of Sydney), Australia; ${ }^{2}$ Precision Agriculture Research Group (University of New England), Australia

Background Available data on quad bike use in Australia is limited by the subjectivity of self-report.

Aim This study sought to ascertain the pattern of usage by geospatial techniques in a small sample of Australian dairy farmers and compare this to self-reported data.

Method The quad bikes of 11 dairy farmers were fitted with two GPS units for a period of 14 days. High temporal resolution data was collected to determine speed by recording five locations $15 \mathrm{~s}$ apart at 5 min intervals for the first 2 days. Data from the 14-day period (with single locations recorded every $5 \mathrm{~min}$ ), were used to assess usage patterns and exposure. These data were compared to selfreport data obtained prior to and immediately following the test period.

Results The majority of usage was at speeds less than $10 \mathrm{~km} / \mathrm{h}$ $(80 \%)$, with the average speed being $9 \mathrm{~km} / \mathrm{h}$. This compared to the self-reported mean of $19 \mathrm{~km} / \mathrm{h}$. Other calculations of rider exposure were also attained.

Significance This is the first study to objectively report on speed and rider exposure in Australian dairy farmers. In general terms average speeds defined by self-report were over-estimated by $10 \mathrm{kmph}$. The predominance of low speed use has implications for the type of helmets required on dairy farms. Further, this may provide an opportunity to increase helmet use compliance and reduce head injury. 